\title{
What will a facial plastic surgeon look like in 2075?
}

\author{
Volume 4 Issue 4 - 2016
}

\section{Opinion}

"Was there really a time when kids could die from strep throat?" This was a question my 12-year-old posed while we were at the International Museum of Surgical Sciences viewing an exhibit on the discovery of antibiotics. She seemed astonished to learn that there was a time when antibiotics did not exist. Even as a physician, I too had to take a moment to appreciate the impact antibiotics has had on medicine and humanity. I then thought to myself; 25years from now, will my daughters' children be asking her if there was a time when people died from cancer?

My grandmother, who was born in 1897, never could have imagined radio, telephones, automobiles, airplanes and answering machines. I always thought if someone were to tell her that one day she could pick up a hand piece, speak into it and have a real-time conversation with another person half-way around the world, she would have never understood. Nor would she accept the possibility of getting into a 500ton metal object and flying through the air over an ocean, and in less than 12 hours, be visiting family members. In my mother's lifetime, has witnessed air conditioning, television and remote controls. I have already seen the invention and advancement of cell phones, computers and the internet. And with technology doubling every 18 months, what will the future hold for us, our children and our profession?

Recently, I've had the opportunity to consider that very notion. I was invited to participate in a think tank sponsored by a division of Nestle, who is committing to establishing the future of educating both doctors and consumers on dermatologic and aesthetic skin health. The Project is called SHIELD, and it stands for Skin Health Investigation Education Longevity Development. They have earmarked funds to open multiple SHIELD centers across the continents. The first one to open is in New York in a few months.

These futuristic think pods are certain to be idealized crosses between an Apple ${ }^{\mathrm{TM}}$ Store and an outer space laboratory. Like nodes they will be linked electronically and virtually so that in real-time free flowing ideas and resources can incubate. The SHIELD pods will be open to anyone with a brilliant idea on skin health who lacks access to universities or research centers or for those who want to bypass the hierarchies and hurdles that may exist in such institutions. Groups of individuals from all aspects of life and all fields of arts, humanities and science will have a chance to meet and interact with each other and brainstorm the future. Great ideas whether conceived in isolation or within the multidiscipline groups will be eligible for funding or triage to the most appropriate outlet. For the creative innovator with the next big idea and no place to go with it, the SHIELD centers will serve as an inviting community to cultivate and grow an idea. The premise is bold and exciting and until now, nothing like it has existed. To think about what medical education and our field will look 60years from now is awe inspiring.

To this extent, last week I read an article on the recent uncovering of post cards from French artists who in the year 1900 painted pictures of what they predicted the future would look like in the year

\author{
Steven Dayan \\ Facial Plastic Surgeon, DePaul University, USA
}

Correspondence: Steven Dayan, Facial Plastic Surgeon, DePaul University, 845 N. Michigan Ave, Suite 923, Chicago Illinois, USA, Tel: 3 I 2335 2070; Email drdayan@drdayan.com

Received: July 19, 2016 | Published: August 05, 2016

2000. ${ }^{1}$ Most were measurably off from today's reality, but a few were rather close. So it got me wondering.. what will future have in store for our specialty? In the spirit of free thinking, I thought I would offer up 10 predictions for what Facial Plastic Surgery will look like in the year 2075 .

a. Non- surgical treatments will continue to grow exponentially outpacing surgical.

b. Facelifts as we know them today will rarely be performed in 2075. In fact, across all the surgical fields the actual cutting open of skin with a scalpel will become a rare last resort measure only called for in emergencies or unusual situations. And rarely will surgery be indicated for cosmetic reasons.

c. Rhinoplasty will still remain the most difficult of all cosmetic procedures and the last cosmetic surgical procedure to be done in large numbers, however, true rhinoplasty as we perform it today will be significantly decreased in numbers. For the primary rhinoplasty, 3D printers will be able to create a nasal skeletal structure composed of an absorbable material that can be inserted just under the skin and act as scaffolding. And along with filler, the two will be used to finely shape the nose into a predetermined ideal structure in just minutes.

d. Surgical training, proficiency and certification will be based on simulators as residencies will have to adapt to the decrease in surgical case loads.

e. Topical translucent products embedded with sunscreen will be topically spread on the skin much like a cosmetic foundation. The product will polymerize and become imperceptible to the eye or touch yet completely smooth out the wrinkles and homogenize the skin texture and tone. It will come in different colors and shades, dyschromias will be camouflaged and tanning will become obsolete. Expect it to also lift and tighten the skin and be removable at the end of the day.

f. Health and wellness strategies such as nutraceuticals possibly hormone replacements, genetic medicine, yoga and more will become part of our practices. Likely the days of solo private practice in Facial Plastic Surgery will come to an end and we will work in multidisciplinary groups offering services and products that can meet the lifestyle request of a modern generation. 
g. Aesthetics will be used to treat mood disorders from depression to anxiety and it will be a reimbursable procedure.

h. Aesthetic Academic societies that at one time were adversarial will recognize their mutually aligned interest and work together closely. They also likely will become more distant from their parent organization. (Keep in mind that no one would have imagined 75years ago that Germany and Japan would be two of the United States most trusted and reliable allies!).

i. Academic meetings will be available to us both virtually and in person. We will have the option to attend via our avatars. Podiums, screens and PowerPoint's will be replaced by large circular meeting rooms where everyone participates freely and democratically. Each will be logged in with their personal hand held device to view, interact and communicate with anyone else in the room at the same time.

j. Facial Plastic Surgery will be one of, if not the most highly coveted and desirable fields in surgery. As the anatomy and nuances of the head and neck are so intricate, important to selfawareness and recognition it will be the last and perhaps only field of medicine to not be commoditized. The best of each medical school class will be drawn to the field due to its reigning autonomy and the ability for a physician to be appreciated for his or her individual expertise. Remote devices products and surgical robotics will not be able to fully replace the hand-eye coordination, artistic sense and more importantly, decision making process necessary to working in what is perhaps the most identifying part of the human body.

k. Perhaps like many of the French painters I'll be off the mark; but maybe some of them will be right on. Either way, it's fun to consider. These are just a few of my predictions, what would be yours?

\section{Acknowledgments}

None.

\section{Conflicts of interest}

Author declares there are no conflicts of interest.

\section{Funding}

None.

\section{References}

1. http://www.fastcoexist.com/1680400/100-years-ago-french-artistspredicted-the-future-with-eerie-accuracy 